\title{
Araştırma ve Geliştirme (Ar-Ge) Harcamalarının Karlılık ve Satışlar Üzerine Etkisi
}

\author{
Tolga ORAL ${ }^{1}$ ve Erhan POLAT ${ }^{2}$
}

Öz

Ar-Ge, yeni uygulamalar tasarlamak amacıyla yapılan çalışmaların toplamı olarak ifade edilmektedir. Şirketlerin rekabet üstünlüğü ve sürdürülebilirliği açısından yeni uygulamalar geliştirilmesi ve hayata geçirilmesi oldukça önemlidir. Bu nedenle şirketlerin Ar-Ge harcamalarına ayırdıkları bütçe her geçen gün artış eğilimindedir. Bu çalışmanın amacı, Ar-Ge harcamalarının satışlar, net kar ve brüt kar üzerindeki etkisini tespit etmektir. Bu amaç doğrultusunda BISTT 30 endeksinde yer alan 14 şirketin 2009-2019 yılları arasındaki Ar-Ge harcamalarının net kar, brüt kar ve satışlara etkisi statik panel veri analizleri aracıllğıyla analiz edilmiştir. Çalışma sonucunda Ar-Ge harcamalarının net kar, brüt kar ve satışları pozitif yönde ve anlamlı şekilde etkilediği belirlenmiştir.

Anabtar Kelimeler: Araştırma ve Geliştirme, Ar-Ge Harcamaları, Net Kar, Satışlar

The Effect of Research and Development (R\&D) Expenses on Profitability and Sales

\begin{abstract}
R\&D is expressed as the sum of the work done to design new applications. It is very important to develop and implement new practices for companies' competitive advantage and sustainability. For this reason, the budget allocated by companies for $\mathrm{R} \& \mathrm{D}$ expenditures is increasing day by day. The purpose of this study is to determine the effect of R\&D expenditures on sales, net profit and gross profit. For this purpose, the effect of R\&D expenditures of 14 companies included in the BIST 30 index between 2009-2019 on net profit, gross profit and sales was analyzed through static panel data analysis.. As a result of the study, it was determined that R\&D expenditures positively and significantly affect net profit, gross profit and sales.
\end{abstract}

Key Words: Research and Development, R\&D Expenditure, Net Profit, Sales

\section{Atıf İçin / Please Cite As:}

Oral, T., Polat, E. (2021). Araştırma ve Geliştirme (Ar-Ge) Harcamalarının Karlılık ve Satışlar Üzerine Etkisi. Manas Sosyal Araștırmalar Dergisi, 10(3), 1878-1888.

Geliş Tarihi / Received Date: 20.02.2021

Kabul Tarihi / Accepted Date: 27.04.2021

\footnotetext{
${ }^{1}$ Dr. Öğr. Üyesi - İnönü Üniversitesi İktisadi ve İdari Bilimler Fakültesi, tolga.oral@inonu.edu.tr

(D) ORCID: 0000-0002-7173-8171

2 Dr. Öğr. Üyesi - Mardin Artuklu Üniversitesi İktisadi ve İdari Bilimler Fakültesi, rhanpolat@artuklu.edu.tr

iD ORCID: 0000-0002-1478-637X
} 


\section{Giriş}

Küreselleşen dünyada şirketlerin rekabet edebilmeleri ve yaşamlarını sürdürebilmeleri bilimsel ve teknolojik ilerlemelere dayalı yenilik üretmeyle yakından ilişkilidir. Şirketlerin yenilik üretme kapasitesi, ekonomik kaynaklarla ve bu kaynakları etkin kullanma ile doğru orantılıdır. Yoğun rekabet ortamında sürdürülebilir kar elde etme ve faaliyetlerini sürdürmek isteyen şirketler, üretim süreçlerine yeniliğe açık bir düşünce benimseyerek satışlarını arttırmayı hedeflemektedirler. Bu açıdan ürünlerde farklılaşma ve kalite sağlanması için sürekli bir gelişim göstermek zorundadırlar. Bu anlayış şirketleri sürekli daha iyiye yöneltmekte ve yeniliği şirket hedefleri arasına almaktadır.

Yenilik sağlayarak üretim süreçlerinde iyileştirmelerin sağlanması ancak bu konuda yapılacak araştırma ve geliştirme faaliyetleri ile mümkün olmaktadır. Ar-Ge yatırımları ile üretim süreçlerinde iyileștirme, yeni ürün geliştirme ve bu sayede satışların artması ile karlılığın sağlanması hedeflenmektedir. Sürdürülebilirlik ve rekabet avantajı sağlama noktasında da Ar-Ge harcamalarının etkisi oldukça önemlidir. Yeni ürün ya da hizmetlerin ortaya çıkarılması, mevcut ürün veya hizmetlerde yenilik sağlanması Ar-Ge olarak ifade edilebilmektedir.

Şirketlerin, piyasada var olabilmesi ve süreklilik açısından var olan bilgiyi ve teknolojiyi geliştirmesi, yeni düşünce ve teknikler yaratması, müşteri ihtiyaçlarına cevap vermesi, gelişimi sürekli kılması ve yeniliği rakiplerinden hızlı yakalayabilmesi gerekmektedir (Ünal ve Seçilmiş, 2014, s. 203). Bu açlardan bakıldığında Ar-Ge harcamaları şirketin rekabet gücüne etki edecek sonuçlar doğurmaktadır. Şirketlerin satışlarının artması ve sürdürülebilir bir karlılığın sağlanması bu sonuçlar arasında yer alması muhtemeldir. $\mathrm{Bu}$ nedenle Ar-Ge yatırımları şirketleri rakiplerine göre daha avantajlı hale getirmede ve şirketlerin teknolojik ilerlemesine katkı sağlamaktadır. Günümüzde bu durum şirketlerin Ar-Ge harcamalarının payının giderek artması ile de kendini göstermektedir. Teknolojik olarak yeniliği takip etmek isteyen ve sürekli gelişim göstermek isteyen şirketlerin yatırım bütçelerinin büyük kısmı Ar-Ge'ye ayrılmaktadır.

Bu çalışmanın amacı, Ar-Ge harcamalarının şirketlerin satışları ve karları üzerinde yarattı̆̆ etkiyi tespit etmektir. İlgili literatürde Ar-Ge harcamalarının karlılık üzerine etkisine yönelik çok sayıda çalışma bulunmaktadır. Bu çalışmada satışların da Ar-Ge harcamalarından etkilenip etkilenmediğini belirlemeye çalışılmıştır. Bu amaç doğrultusunda literatürdeki çalışmalar özetlendikten sonra söz konusu etkinin tespit edilmesine yönelik BİST 30 endeksinde yer alan 14 şirketin 2009-2019 yılları arasındaki net kar, brüt kar ve satış verileri kullanılarak statik panel veri analizi gerçekleştirilmiştir.

\section{Literatür Özeti}

Ar-Ge harcamalarının karlllık ve finansal performans üzerine etkisi konusundan yerli ve yabanc1 literatürde çok sayıda çalışma bulunmaktadır. Bu çalışmalardan bazıları aşağıda özetlenmiştir.

Scherer (1965), yaptı̆̆ çalısmada, 448 şirketin 1955-1959 yıllarındaki verilerini kullanarak regresyon analizi gerçekleştirmiştir. Çalışmanın sonucunda, Ar-Ge faaliyetlerinin satışları artırı̆ı̆ı ve dolaylı olarak karlılığın da arttığını tespit etmiştir.

Geroski ve Toker (1996), 1979-1986 yılları İngiltere İmalat firmaları verileri üzerine regresyon analizi gerçekleştirmiştir. Çalışma sonucunda, Ar-Ge faaliyetleri ile satışlar arasında güçlü ve pozitif bir ilişki olduğu belirlenmiştir.

Coad ve Rao (2008), Amerikan firmaları arasında yüksek teknolojiye sahip olanlar üzerinde regresyon analizi gerçekleştirmiştir. Çalısma sonucunda, bazı firmalarda Ar-Ge harcamalarının ve patent sayısının düşük performansa ve satışların düşmesine neden olduğu tespit edilmiştir.

Çıtak ve İltaş (2017), Bist Teknoloji endeksinde yer alan şirketlerin 2013-2015 yıllarındaki verileri veri zarflama analizi ile değerlendirmiştir. Çalışma sonucunda, şirketlerin say teknik etkinlik düzeylerinin göreceli olarak yüksek olduğunu tespit etmişlerdir.

Erdoğan ve Yamaltdinova (2019), 2008-2017 döneminde Borsa İstanbul'da işlem gören 62 üretim şirketinin verilerini panel veri analizi ile incelemiştir. Çalışma sonucunda Ar-Ge harcamaları ile finansal performans arasında pozitif bir ilişki olduğu tespit edilmiştir.

Özer, Öztürk ve Özer (2019), 2012-2017 döneminde Borsa İstanbul'da işlem gören imalat sanayi şirketlerinin verilerini panel veri analizi ile incelemiştir. Çalışma sonucunda, statik panel modeline göre Ar- 
Ge harcamalarının piyasa değeri ve karlılık üzerinde etkisinin olmadığı, dinamik panel modeline göre ise pozitif etkisinin olduğu belirlenmiştir.

Uzun Kocamış ve Güngör (2014), 2009-2013 ylları arasında Borsa İstanbul'da işlem gören teknoloji şirketlerinden 16 şirketin finansal performans verileri regresyon analizi ile incelemiştir. Çalışma sonucunda, Ar-Ge harcamaları ile karlılık değerleri arasında pozitif yönlü bir ilişki olduğu belirlenmiştir.

Hajiheydari, Dastgir ve Soltani (2011), dünya çapında ve çok uluslu 20 ilaç şirketinin verilerini regresyon analizi ile incelemiştir. Çalışma sonucunda, Ar-Ge maliyetleri ile karlllık arasında güçlü ve pozitif yönlü bir ilişki tespit edilmiştir.

Gün ve Yerdelen Kaygin (2020), 2010-2019 y1lları arasında BIST TUM endeksinde yer alan şirketlerin verilerini veri zarflama analizi ile incelemişlerdir. Çalışma sunucunda, GENTS ve KOZAA şirketlerinin en yüksek etkinlik düzeyine sahip olduğu belirlenirken; OTKAR ve ULKER şirketlerinin ise en düşük etkinlik düzeyine sahip olduğu belirlenmiştir.

Günay, Kaygısız ve Ayar (2018), 2012-2016 yılları arasında Borsa İstanbul'da işlem gören 16 teknoloji şirketinin verilerini analiz etmiştir. Çalışma sonucunda, Ar-Ge harcamaları ile kar değişkenleri arasında güçlü ve pozitif yönlü bir ilişki olduğu tespit edilmiştir.

Işı1k, Engeloğlu ve Kılınç (2016), Ar-Ge harcamaları ile satış ve karlılık arasındaki ilişkiyi incelemişlerdir. Çalışma sonucunda, Ar-Ge harcamaları ile satış ve karlılık arasında pozitif ve anlamlı bir ilişki olduğu tespit edilmiştir.

Güzen ve Başar (2019), 2012-2018 yılları arasında BIST sınai endeksinde yer alan şirketlerin verilerini panel veri analizi ile incelemiştir. Çalışma sonucunda, Ar-Ge harcamalarının faaliyet karını cari dönemde azalttığı, sonraki dönemlerde arttırdığı tespit edilmiştir. Ayrıca satış gelirlerinin artması karllı̆̆ı̆nda artmasına neden olduğu belirlenmiştir.

Ayaydın ve Karaaslan (2014), 2008-2013 yılları arasında 145 imalat şirketinin verilerini panel veri analizi ile incelemiştir. Çalşsma sonucunda, şirketlerin Ar-Ge harcamaları ile finansal performansları arasında güçlü ve pozitif bir ilişki olduğu tespit edilmiştir.

\section{Yöntem}

\section{Ekonometrik Analiz}

Bu çalışmada firmaların AR-GE yatırımlarının net kar, brüt kar ve satışlara etkisini analiz etmek amacıyla statik panel veri analizlerinden yararlanılmıştır. Katsayı tahminlerine yönelik analizlere başlanmadan önce serilerde yatay kesit bağımlilı̆̆ test edilerek uygun panel birim kök testine karar verilmiştir. Sonrasında uygun panel veri yöntemini seçebilmek için F testi, LR testi ve Hausman testlerinden yararlanılmıştır. Bir önceki aşamada modeller bazında elde edilen bulgulara göre sabit etkiler ve tesadüfi etkiler modellerinin kullanılabileceğine karar verilmiştir. Her bir model için değişen varyans, otokorelasyon ve birimlerarası korelasyon sorunları araştırılmış ve elde edilen sonuçlara göre de uygun dirençli tahminciler kullanılarak analizlerimiz sonlandırılmıştır.

\section{Model ve Veri}

AR-GE harcamalarının (AR-GE); net kar, brüt kar ve satışlara etkisini açıklamak için aşağıdaki ekonometrik modeller kullanılmıştır:

$$
\begin{aligned}
& \text { Model 1: Net Kar=f(AR-GE) } \\
& \text { Model 2: Brüt Kar= f(AR-GE) } \\
& \text { Model 3: Satışlar= f(AR-GE) }
\end{aligned}
$$

Ekonometrik tahminler yapıllırken modeldeki değişkenlerin logaritmik dönüşümleri gerçekleştirilmiştir. Ekonometrik modellerin logaritmik dönüşümlerini içeren şekillerine aşağıda yer verilmiştir:

$$
\begin{aligned}
& \text { Model 1: } \ln N e t K a r i t=\alpha i t+\beta 1 \ln A R-G E i t+\text { sit } \\
& \text { Model 2: } \operatorname{lnBrütKarit~}=\delta \text { it }+u 1 \ln A R-G E i t+\varepsilon i \\
& \text { Model 3: lnSatışlarit }=\pi \mathrm{it}+\Theta 1 \ln A \mathrm{R}-\mathrm{GEit}+\text { sit }
\end{aligned}
$$


Denklemlerde i $(1,2,3, \ldots . ., 14)$ yatay kesit verilerini, $t(2009,2010,2011, \ldots .2019)$ zaman boyutunu, $\beta 1$, 1 ve $\Theta 1$ AR-GE harcamalarının her bir modeldeki esneklik katsayılarını ve $\varepsilon$ ise hata terimini temsil etmektedir.

Bu çalışmada 2009-2019 döneminde ( www.kap.gov.tr) AR-GE harcamalarının net kar, brüt kar ve satışlara etkisi BIST 30'da yer alan 14 firma ( ARCLK, ASELS, EREGL, SAHOL, KCHOL, KOZAL, KOZAA, PETKM, SODA, TKFEN, TOASO, TRKCM, TUPRS, SISE) için incelenmektedir (www.borsaistanbul.com).

\section{Analizde Kullanılan Testlere Ait Teorik Çerçeve}

\section{Önsel testler: yatay kesit bağımlılı̆̆1 testi ve Im-Pesaran-Shin (IPS) birim kök testi}

Panel veri analizlerine başlamadan önce yatay kesit bağımlılı̆̆nın incelenmesi tutarlı sonuçların elde edilmesi için önemlidir. Bu çalışmada serilerde yatay kesit bağımlılığının varllğının incelenmesi amacıyla Pesaran vd. (2008) tarafindan geliştirilen ve $\mathrm{T}>\mathrm{N}$ ve $\mathrm{N}>\mathrm{T}$ durumlarında bile tutarlı sonuçların elde edilmesine yardımcı olan LM testi (LMadj) kullanılmaktadır (Pesaran vd., 2008). Aşağıdaki denklem LM testine ait açılamaları içermektedir.

$$
L M=\sqrt{\frac{1}{N(N-1)}}\left(\sum_{i=1}^{N-1} \sum_{j=i+1}^{N} T \rho_{i j}^{2}-1\right)
$$

Denklemdeki N birim ve T zamanı göstermektedir. Bu testte sıfir hipotezi yatay kesit bağımlıllğının olmadığını varsayar iken; alternatif hipotez panel veride yatay kesit bağımlılı̆̆ının olduğunu ifade etmektedir.

Modeli tahmin etmeden önce serilerde durağanlık olup olmadığı kontrol edilmelidir. Çünkü, durağan olmayan serilerde test istatistiklerinin güvenilir olmadığ1 ve modellerin de sahte regresyon içerdiği sorunları ortaya çıkabilmektedir. Birim kök testleri serilerde yatay kesit bağımlılı̆̆ının olmadığı durumda kullanılabilen birinci nesil birim kök testleri ve yatay kesit bağımlllğının olduğu durumda kullanılabilen ikinci nesil birim kök testleri ile sınanmaktadır. Bu çalışmada yatay kesit bağımlılı̆ının olmadığı durumdan hareketle birinci nesil birim kök testi olan Im-Pesaran-Shin (IPS, 2003) testi kullanılmıştır. IPS (2003) testi, panel veri setinde tek tek birimler için hesaplanan t istatistiği ortalamasını dikkate almaktadır. IPS testinde, "tüm birimler için birim kök yoktur" şeklinde kurulan sıfır hipotezinin red edilmesi durumunda serilerde birim kökün olduğu sonucuna ulaşılmaktadır.

\section{Uygun Panel Veri Yönteminin Belirlenmesi: LR, F ve Hausman Testleri}

Panel regresyon modelleri havuzlanmış en küçük kareler modeli (EKK), sabit etkiler modeli ve tesadüfi etkiler modeli şeklinde üç gruba ayrılmaktadır. EKK yöntemi sabit ve eğim katsayılarının yatay kesitlere (birim) göre değişmediği varsayımına dayanmaktadır. Sabit etkiler ve tesadüfi etkiler modellerinde ise birim ve zaman farklılıklarının etkileri dikkate alınmaktadır. Ancak sabit etkiler modelinde birim farklılıklarının ortaya çıkardığı etkiler modele dahil edilirken; tesadüfi etkiler modelinde zaman etkilerinin ortaya çıkardığı etkiler model ilave edilmektedir (Topal ve Günay, 2017, s. 72).

AR-GE harcamalarının net kar, brüt kar ve satıslara etkisini belirleyebilmek için sabit etkiler, tesadüfi etkiler ve havuzlanmış EKK modellerinden hangisi/hangilerinin kullanılacağına $F$ testi, olabilirlik oranı testi (LR) ve Hausman testi sonuçlarına göre karar verilmektedir. F testinde, havuzlanmış EKK modelinin uygun olduğunu ifade eden sıfir hipotezinin reddedilmesi durumunda sabit etkiler modelinin geçerli olduğu sonucuna varılmaktadır. LR testinde, sıfır hipotezi havuzlanmıs EKK modelinin uygun olduğunu ancak reddedilmesi durumunda tesadüfi etkiler modelinin geçerli olduğunu ortaya koymaktadır. Sabit ve tesadüfi etkiler modeli arasında seçim yaparken Hausman testinden yararlanılmaktadır. Hausman testinde tesadüfi etkiler modelinin uygun olduğu şeklinde kurulan sıfır hipotezi, sabit etkiler modelinin geçerli olduğu alternatif hipoteze karşı sınanmaktadır. Bu çalışsmada Model 1 ve Model 2 için uygun modelin sabit etkili model ve Model 3 için tesadüfi etkili model olduğu belirlenmiştir.

\section{Değişen Varyans, Otokorelasyon ve Birimlerarası Korelasyon Testleri}

Tahmin edilen modellerde yanlı ve tutarsız sonuçlara sebep olan sorunlar değişen varyans, otokorelasyon ve birimlerarası korelasyondur. Sabit varyans varsayımının geçerli olmadığını ifade eden 
değişen varyans, hata terimlerinin varyanslarının tüm kesitler için farklı olduğu ve kovaryanlarının sıfıra eşit olmaması olarak açıklanmaktadır. Otokorelasyon ise, hata teriminin birbirini izleyen değerleri arasındaki anlamlı ilişkiyi ifade etmektedir (Topaloğlu, 2018, s. 28).

Dolayısıyla, bu çalışmada daha etkin sonuçların elde edilebilmesi ve yanlı tahminlerden sakınılması amacıyla değişen varyans sorununun olup olmadığına Model 1 Model 2 için Breusch-Pagan-Godfrey değişen varyans LM testi ile Model 3 için Levene, Brown ve Forsythe değişen varyans testi ile incelenmiştir. $\mathrm{Bu}$ testlerde sıfır hipotezi modellerde değiş̧en varyansın olmadığını ifade etmektedir. Modellerin otokorelasyon sorunu taşıyıp taşımadığına karar verilebilmesinde Bhargava, Franzini ve Narendranathan (1982)'in geliştirdiği Durbin-Watson testi kullanılmıştır. Bu testtin istatistiği 2'den küçük ise modellerde otokorelasyonun olduğu anlamına gelmektedir. Varsayımların geçerliliğini önleyen diğer bir sorun olan birimler arası korelasyonun varlığı ise Pesaran (2004)'in geliştirmiş olduğu CD-testiyle araştırılmıştır. Modellerde yatay kesit bağımlılığının olduğu sonucuna sıfir hipotezinin reddi durumunda karar verilebilmektedir.

Tahmin edilen modellerde bu tür sorunların var olması durumunda değişkenler arasındaki ilişkilerin tutarlı olabilmesi için dirençli tahmincilerden yararlanılarak tahminlerin yenilenmesi gerekmektedir (Tatoğlu, 2012, s. 241). ve modellerin tahmin edilmesinde varsayımlardan sapmalara neden olan sorunları çözülebilen Driscoll-Kraay (1998) ve Beck-Katz (1995) dirençli tahminciler kullanılmıstır.

\section{Bulgular}

Ekonometrik analizler modellerde yatay kesit bağımlılığının varlığını kontrol etmekle başlamaktadır. Tablo 1, yatay kesit bağımlılı̆ının test edilmesinde kullanılabilen Pesaran vd. (2008) tarafindan geliştirilen LMadj istatistiğine ait sonuçları içermektedir. Tablo 1'e göre bütün modellerde sıfir hipotezi kabul edilmekte ve serilerde yatay kesit bağımlılı̆̆ının olmadığı sonucuna ulaşılmaktadır.

Tablo 1. Yatay Kesit Bă̆zmllhğ Testi Sonuçları

\begin{tabular}{llc}
\hline & Test & \multicolumn{1}{c}{$\begin{array}{c}\mathbf{L M}_{\text {adj }} \\
\text { (Pesaran vd., 2008) }\end{array}$} \\
\hline \multirow{2}{*}{$\ln$ AR-GE } & Test İstatistiği & -0.577 \\
& P-Değeri & $(0.718)$ \\
\hline \multirow{2}{*}{$\ln N$ et Kar } & Test İstatistiği & -0.342 \\
& P-Değeri & $(0.634)$ \\
\hline \multirow{2}{*}{$\ln$ Brüt Kar } & Test İstatistiği & -0.475 \\
& P-Değeri & $(0.683)$ \\
\hline \multirow{2}{*}{$\ln$ Satışlar } & Test İstatistiği & 0.779 \\
& P-Değeri & $(0.218)$ \\
\hline
\end{tabular}

Serilerde yatay kesit bağımlılığının olmadığı sonucundan hareketle değişkenlerin durağanlık sınaması birinci nesil birim kök testi ile incelenmelidir. Bu amaçla, çalışmada değiş̧kenlerin durağanlık sınamasında IPS birim kök testi kullanılmıs ve testlerin sonuçları Tablo 2'de gösterilmiştir.

Tablo 2. IPS Birim Kök Testi Sonuçlar

\begin{tabular}{cccccccc}
\hline \multicolumn{2}{c}{ lnNet Kar } & \multicolumn{2}{c}{ lnBrüt Kar } & \multicolumn{2}{c}{ lnSatıslar } & \multicolumn{2}{c}{ lnAR-GE } \\
\hline \multirow{2}{*}{ Düzey } & Birinci & \multirow{2}{*}{ Düzey } & Birinci & \multirow{2}{*}{ Düzey } & Birinci & Düzey & Birinci Fark \\
& Fark & & Fark & & Fark & & \\
\hline 2.4124 & $-3.634^{*}$ & 4.665 & $-2.199^{* *}$ & 4.483 & $-1.952^{* *}$ & 2.769 & $-2.313^{*}$ \\
$(0.9921)$ & $(0.0001)$ & $(1.0000)$ & $(0.0139)$ & $(1.0000)$ & $(0.0254)$ & $(0.9972)$ & $(0.0104)$ \\
\hline
\end{tabular}

Not: *. ** ve $* * *$ serilerin sırasılla \%1, \%5 ve \%10 düzeyinde durağan olduğunu göstermektedir. Parantez içindeki değerler olasılık değerlerini ifade etmektedir.

Birim kök testinden sonra modeller için LR, F ve Hausman testlerinden yararlanılarak uygun panel veri yöntemi belirlenmiş ve testlerin sonuçlarına Tablo 3 'te yer verilmiştir.

Tablo 3 incelendiğinde Model 1'de F testi sonuçlarına göre olasılık değeri kritik değerden büyük olduğundan dolayı sıfir hipotezinin reddine karar verilmiştir. Diğer bir deyişle modelin tahmin edilmesinde uygun yöntem sabit etkiler modelidir. LM testinde olasılık değeri kritik değerden küçük olduğu için tahmin edilecek etkin model EKK modeli yerine tesadüfi etkiler modelidir. Son olarak Hausman testinde olasillk değeri kritik değerden küçük olduğu için sabit etkiler modelinin kullanılarak tahminlerin yapılabileceğini göstermiştir. 
Aynı tabloda Model 2 için de sonuçlar yer almaktadır. Buna göre F testi sonuçları sabit etkiler modelini uygun tahminci olarak seçmiştir. LM testi sonuçları tesadüfi etkiler modelini destekler iken; Hausman testi sıfır hipotezinin reddedilmesiyle birlikte sabit etkiler modelinin uygunluğuna karar vermiştir.

Tablo 3. F, LR ve Hausman Testi Sonuclar

\begin{tabular}{|c|c|c|c|c|c|c|c|}
\hline Test & Hipotezler & Model 1 & Karar & Model 2 & Karar & Model 3 & Karar \\
\hline \multirow[b]{2}{*}{ F Testi } & $\begin{array}{l}H_{0}: \text { EKK } \\
\text { geçerli }\end{array}$ & $15.37^{*}$ & Ho red & $30.36^{*}$ & Ho red & $124.84^{*}$ & \multirow[t]{2}{*}{ Ho red } \\
\hline & $\begin{array}{l}H_{1}: \text { Sabit } \\
\text { etkiler gegerli }\end{array}$ & $(0.0000)$ & & $(0.0000)$ & & $(0.0000)$ & \\
\hline \multirow{2}{*}{ LR Testi } & $\begin{array}{l}H_{0}: \text { EKK } \\
\text { geçerli }\end{array}$ & $11.60^{*}$ & Ho red & $8.99 *$ & Ho red & 0.01 & \multirow[t]{2}{*}{ Ho kabul } \\
\hline & $\begin{array}{l}H_{1}: \text { Tesadüfi } \\
\text { etkiler geçerli }\end{array}$ & $(0.0003)$ & & $(0.0014)$ & & $(0.4587)$ & \\
\hline \multirow{2}{*}{$\begin{array}{l}\text { Hausman } \\
\text { Testi }\end{array}$} & $\begin{array}{l}H_{0}: \text { Tesadüfi } \\
\text { etkiler geçerli }\end{array}$ & $9.20^{*}$ & \multirow[t]{2}{*}{$\begin{array}{c}\text { Ho } \\
\text { kabul }\end{array}$} & $4.89 * *$ & Ho red & 1.65 & \multirow[t]{2}{*}{ Ho kabul } \\
\hline & $\begin{array}{l}H_{1}: \text { Sabit } \\
\text { etkiler gecerli }\end{array}$ & $(0.0041)$ & & $(0.0270)$ & & (0.1984) & \\
\hline
\end{tabular}

Not: *,** ve *** sırasıyla \%1, \%5 ve \%10 anlamlllık düzeyini göstermektedir. Parantez içi p-değerini göstermektedir.

Model 3'e ait sonuçlar ise F testi açısından sabit etkiler modelini doğru tahminci olarak belirlerken, LR testi sonuçları EKK'yı desteklemiştir. Netice de Hausman testi sonucu olasılık değerinin kritik değeri aşmasından dolayı uygun tahmin yönteminin tesadüfi etkiler modeli olduğunu ortaya koymuştur.

Bu çalışmada modeller için değişen varyans, otokorelasyon ve birimler arası korelasyon testleri sonuçları Tablo 4'te gösterilmiştir.

Tablo 4. Değişen Varyans, Otokorelasyon ve Birimlerarası Korelasyon Testleri Sonuclar

\begin{tabular}{|c|c|c|c|c|}
\hline Test & & Model 1 & Model 2 & Model 3 \\
\hline \multicolumn{5}{|l|}{ Değişen Varyans } \\
\hline Breusch-Pagan-Godfrey & İstatistik Değeri & & & $\mathrm{W} 0=2.3624943^{*}$ \\
\hline LM testi & & $3628.4 *$ & 953.21* & $\mathrm{W} 50=1.1791955$ \\
\hline Levene, Brown ve & & & & $\mathrm{W} 10=2.0770828^{*}$ \\
\hline Forsythe testi & P-değeri & 0.0000 & 0.0000 & 0.0000 \\
\hline \multicolumn{5}{|l|}{ Otokorelasyon } \\
\hline \multirow{3}{*}{ Durbin-Watson } & İstatistik Değeri & & 1.0322326 & \\
\hline & & 1.4063999 & $1.03225 \angle 0$ & 0.59925595 \\
\hline & P-değeri & - & - & - \\
\hline \multicolumn{5}{|l|}{ Birimleraras1 Korelasyon } \\
\hline \multirow[b]{2}{*}{ CD testi } & İstatistik Değeri & 193.818 & 246.149 & 13.751 \\
\hline & P-değeri & 0.0000 & 0.0000 & 0.0000 \\
\hline
\end{tabular}

Not: *, \%1 anlamlllık düzeyini göstermektedir.

Değişen varyans varsayımını test etmek amacıyla Model 1 ve Model 2'de Breusch-Pagan-Godfrey değişen varyans LM testinden, Model 3 için Levene, Brown ve Forsythe'nin testlerinden yararlanılmıştır. Model 1 ve Model 2 için Breusch-Pagan-Godfrey LM testinin olasılık değeri 0.05 kritik değerinden küçük olmasından dolayı sıfır hipotezi reddedilmekte ve modellerde değişen varyans sorununun olduğu sonucuna ulaşılmıştır. Model 3 için ise Levene, Brown ve Forsythe testinde olasıllı değeri kritik değerden küçük çıktığı için değişen varyans yoktur şeklindeki sıfir hipotezi reddedilmekte ve dolayısıyla değişen varyansın olduğu ortaya çımaktadır. Model 1, Model 2 ve Model 3'te Durbin-Watson test istatistik değerleri (sırasiyla 1.4063999, 1.0322326 ve 0.59925595) 2'den küçük olduğu için ilgili modellerde otokorelasyon sorununun olduğu kanaatine ulaşılmıştır. Ardından birimler arası korelasyonun varllğı Pesaran (2004) tarafindan geliştirilen $\mathrm{CD}$ testi ile sınanmış ve sonuç olarak modellerin tümünde birimler arası korelasyonun olmadığını ifade eden sıfır hipotezi $\% 1$ anlamlılık düzeyinde reddedilmiştir. Kısaca tüm modellerde birimler arası korelasyon sorunu mevcuttur.

Son aşamada her bir model için değişkenler arasındaki istatistiksel olarak anlamlı bir ilişkinin varlığı, yönü ve büyüklüğü belirlenmeye çalışlmıştır. Çalışmada tahmin edilecek modellerde değişen varyans, otokorelasyon ve birimler arası korelasyon sorununun olması modellerin tahmin edilmesinde dirençli 
ORAL ve POLAT

Araştırma ve Geliştirme (Ar-Ge) Harcamalarının Karlılık ve Satışlar Üzerine Etkisi

tahmincilerin kullanılması gerekliliğini ortaya koymuştur. Bundan dolayı Model 1 ve Model 2 için DriscollKraay ile Model 3 için Beck-Katz tahmincilerinden yararlanılarak tahminler yapıllmış ve Tablo 5'te sonuçlar sunulmuştur. 
Tablo 5. Driscoll-Kraay ve Beck-Katz Tahmincileri Sonuclar

\begin{tabular}{|c|c|c|c|c|}
\hline Bağımlı Değişkenler & & $\operatorname{lnNet}$ Kar & InBrüt Kar & InSatışlat \\
\hline Bağımsız Değişken & & Model 1 & Model 2 & Model 3 \\
\hline \multirow{2}{*}{$\ln A R-G E$} & Katsay1 & $0.779353^{*}$ & $0.6973704^{*}$ & $0.2771189 *$ \\
\hline & Olasılık değeri & 0.0000 & 0.0000 & 0.0000 \\
\hline \multirow{2}{*}{$\mathrm{C}$} & Katsay1 & $5.926767 *$ & $7.256662^{*}$ & $12.93908^{*}$ \\
\hline & Olasılık değeri & 0.0000 & 0.000 & 0.0000 \\
\hline \multirow[t]{2}{*}{$\mathrm{R}^{2}$} & & 0.3313 & 0.5286 & 0.9837 \\
\hline & Katsay1 & $40.78^{*}$ & $48.57^{*}$ & $25.40^{*}$ \\
\hline \multirow[t]{2}{*}{ F İstatistiği } & Olasilık değeri & & & \\
\hline & & 0.0000 & 0.0000 & 0.0000 \\
\hline Gözlem & & 154 & 154 & 154 \\
\hline Firma Say1s1 & & 14 & 14 & 14 \\
\hline
\end{tabular}

Not: * işareti \%1 anlamll11k düzeyini göstermektedir.

Tablo 5'deki tahmin sonuçlarına göre Model 1, Model 2 ve Model 3 için R2 değerleri sırasıyla yaklaşık olarak $\% 33, \% 53$ ve $\% 98$ bulunmuştur. Dolayısıyla firmaların net karlarındaki değişmelerin $\% 33$ ü, brüt karlardaki değişmelerin \%53’ü ve satışlardaki değişmelerin \%08’i AR-GE harcamalarındaki değişmeler tarafindan açıklanabilmektedir. Ayrıca bütün modellerde $\mathrm{f}$ istatistiğinin olasılık değeri $\% 1$ anlamlılık düzeyinde anlamlı bulunduğu için bütün modeller bir bütün olarak anlamlıdır. Tablodaki katsayılar incelendiğinde ise AR-GE harcamalarındaki \%1'lik artısın, firmaların net karlarını yaklaşık olarak $\% 0.78$, brüt karları $\% 0.70$ ve satışları $\% 0.28$ artırdığı ve sonuçların istatistiksel olarak anlamlı olduğu anlaşılmıştır. Bu değerlere göre analize dahil edilen firmaların AR-GE harcamalarının en fazla net karı en az ise satışları artırdığı ortaya çıkmıştır.

\section{Tartışma, Sonuç ve Öneriler}

Bu çalışma firmaların AR-GE harcamalarının net kar, brüt kar ve satışlarına etkisini analiz etmek amacıyla hazırlanmıştır. Bu çerçevede çalışmada 14 firmanın 2009-2019 yıllarını kapsayan AR-GE harcamaları, net kar, brüt kar ve satış değişkenleri arasındaki ilişkilerin sınanmasında statik panel veri analizlerinden yararlanılmışır. Araştırma aşamaları yatay kesit bağımlılı̆ı ve birim kök gibi testlerle başlamış, uygun tahmin yönteminin belirlenmesinde çeşitli testlerden (F testi, LR testi ve Hausman testi) yararlanılmış ve Model 1 ve Model 2 için sabit etkiler modeli, Model 3 için ise tesadüfi etkiler modelinin uygun modeller olduğuna karar verilmiştir. Sonrasında her bir model için değişen varyans, otokorelasyon ve birimler arası korelasyon testleri yapılarak modellerin tamamında bu sorunların var olduğu tespit edilmiştir. Tutarlı ve etkin sonuçların elde edilebilmesi amacıyla Driscoll-Kraay ve Beck-Katz tahmincileri kullanılarak ilgili modeller için tahminler yapılmıştır.

Analizlerde elde ettiğimiz sonuçları şu şekilde özetleyebiliriz: 1) AR-GE harcamaları net karı, brüt karı ve satışları pozitif yönde ve anlamlı şekilde etkilemektedir. 2) AR-GE harcamalarındaki \%1'lik artış firmaların net karlarını yaklaşık olarak $\% 0.78$, brüt karları $\% 0.70$ ve satışları $\% 0.28$ oranında artırmaktadır. 3) Firmaların AR-GE harcamaları en fazla net karı artırırken, en az satışları artırmaktadır. Çalışma kapsamında elde edilen verilere göre AR-GE harcamalarının kar ve satıslar üzerindeki olumlu etkisinin literatür ile uyumlu olduğu (Scherer, 1965; Erdoğan ve Yamaltdinova, 2019; Uzun Kocamış ve Güngör, 2014; Hajiheydari, Dastgir ve Soltani, 2011; Günay, Kaygısız ve Ayar, 2018; Işık, Engeloğlu ve Kılınç, 2016; Güzen ve Başar, 2019; Ayaydın ve Karaaslan, 2014) ve diğer bazı çalışmalar (Coad ve Rao, 2008) ile uyumlu olmadığı gözlemlenmiştir. Ar-Ge harcamalarının daha çok net kar üzerindeki etkisi, bu tür harcamaların firmaların büyümesi üzerinde etkili olduğunu ortaya koyması ile birlikte, firmaların mevcut yatırımdan daha fazla kar elde etmelerine yol açmaktadır. Bu nedenle firmaların AR-GE faaliyetlerine yapacakları yatırımların firma karlılığını arttırmakla ile birlikte ülkelerinde büyümesine katkı sunabileceği söylenebilir. 
Sonuç olarak, firmaların ve politika yapıcıların AR-GE harcamalarına daha fazla yatırım yapmaları yeni ürün ve üretim yöntemlerinin geliştirilmesinde önem arz edecek, firmalara rekabet avantajı sağlayacağ1 gibi ülke ekonomisine de olumlu katkı sunacaktır. Araştırmacıların bundan sonraki çalışmalarında BİST’te yer alan diğer endekslerde AR-GE harcamalarının etkisinin araştırılması önerilmektedir.

\section{Etik Beyan}

"Araștırma ve Gelistirme (Ar-Ge) Harcamalarmm Karlllk ve Satı̧lar Üzerine Etkisi”" başlıklı çalışmanın yazım sürecinde bilimsel kurallara, etik ve alıntı kurallarına uyulmuş; toplanan veriler üzerinde herhangi bir tahrifat yapılmamış ve bu çalışma herhangi başka bir akademik yayın ortamına değerlendirme için gönderilmemiştir. $\mathrm{Bu}$ araştırmada hazır veri seti kullanıldığı için etik kurul kararı zorunluluğu taşımamaktadır.

\section{Kaynakça}

Ayaydın, H. ve Karaaslan, İ. (2014). The effect of research and development investment on firms' financial performance: evidence from manufacturing firms in turkey. Bilgi Ekonomisi ve Yönetimi Dergisi, 9(2), 43-59.

Beck, N. ve Katz, J. (1995). What to do (and not to do) with time-series cross-section data. American Political Science Review, 89(3), 634-647.

Bhargava, A., Franzini, L. ve Narendranathan, W. (1982). Serial correlation and the fixed effects model. The Re-view of Economic Studies, 49(4), 533-549.

Breusch, T. ve Pagan, A. (1980). The lagrange multiplier test and its applications to model specification in econometrics. Review of Economic Studies, 47(1), 239-253.

Coad, A. ve Rao, R. (2008). Innovation and firm growth in high-tech sectors: a quantile regression approach. Research Policy, 37, 633-648.

Çıtak, L. ve İltaş, Y. (2017). Ar-Ge yatırımlarının finansal performans üzerindeki etkisi ve BİST teknoloji endeksi firmalarının etkinliklerinin değerlendirilmesi. Muhasebe ve Finansman Dergisi, 76, 239-254.

Erdoğan, M. ve Yamaltdinova, A. (2019). A panel study of the impact of R\&D on financial performance: evidence from an emerging market. Procedia Computer Science, 158, 541-545.

Geroski, P. ve Toker, S. (1996). The turnover of market leaders in UK manufacturing industry 1979-86. International Journal of Industrial Organization, 14, 141-158.

Gün, M. ve Yerdelen Kaygin, C. (2020). Ar-Ge yatırımlarının finansal performans üzerine etkisinin veri zarflama analizi ile incelenmesi. BMIJ, 8(3), 2649-2674, doi: http://dx.doi.org/10.15295/bmij.v8i3.1539.

Günay, Y., Kaygisız, E. G. ve Ayar, M. (2018). Teknoloji sektöründe Ar-Ge harcamalarının payı: Borsa İstanbul (BİST) örneği. International Journal of Disciplines Economics \& Administrative Sciences Studies, 4(9), 463-473.

Güzen, H. ve Başar, B. (2019). Ar-Ge harcamalarının raporlanması ve kârlllığa etkisi: BİST sınai endeksi işletmeleri üzerine bir araştırma. Anadolu Üniversitesi İktisadi ve İdari Bilimler Fakültesi Dergisi, 20(2), 1-24. Retrieved from http://www.dergipark.org.tr/tr/pub/anadoluibfd/issue/49099/626792

Hajiheydari, A., Dastgir M. ve Soltani, A. (2011). the effect of research and development costs on the profitability of pharmaceutical companies. Interdisciplinary Journal Of contemporary research In Business, 3(8), 914-918.

Im, K., Pesaran, H. ve Shin, Y. (2003). Testing for unit roots in heterogeneous panels. Journal of Econometrics, 115, 5374.

Işık, N., Engeloğlu, Ö. ve Kılınç, E.C. (2016). Araştırma ve geliştirme harcamalarının, kâarlılık ve satışlar üzerindeki etkisi: Borsa İstanbul firmaları üzerine bir uygulama. Erciyes Üniversitesi İktisadi ve İdari Bilimler Fakültesi Dergisi, 47, 27-46.

Özer, A., Öztürk, M. ve Özer, N. (2019). BİST imalat sanayi firmalarının araştırma ve geliştirme giderlerinin piyasa değeri ve firma kârlllığı üzerindeki etkisi . Mubasebe ve Finansman Dergisi, 82, 135-146.

Pesaran, M. H. (2004). General diagnostic tests for cross section dependence in panels. University of cambridge, WorkingPaper, No. CWPE 0435.

Pesaran, M. H., Ullah, A. ve Yamagata, T. (2008). A bias-adjusted $\mathrm{lm}$ test of error cross-section independence. Econometrics Journal, 11, 105-127.

Scherer, M. F. (1965). Corporate inventive output, profits, and growth. Journal of Political Economy, 73(3), 290-297.

Tatoğlu, F. Y. (2012). Panel veri ekonometrisi, İstanbul: Beta Yayıncillk.

Topal, M. H. (2017). Çevre vergilerinin çevre kalitesi üzerindeki etkisi: gelişmekte olan ve gelişmiş ekonomilerden ampirik bir kanit. Maliye Arasttrmalar Dergisi, 3(1), 63-83.

Topaloğlu, E. E. (2018). Bankalarda finansal kırllganlı̆̆1 etkileyen faktörlerin panel veri analizi ile belirlenmesi. Eskişehir Osmangazi Üniversitesi IIIBF Dergisi, 13(1), 15-38.

Uzun Kocamış, T. ve Güngör, A. (2014). Türkiye'de Ar-Ge harcamaları ve teknoloji sektöründe ar-ge giderlerinin kârll11k üzerine etkisi: Borsa İstanbul uygulaması. Maliye Dergisi, 166, 127-138.

Ünal, T. ve Seçilmiş, N. (2013). Ar-Ge göstergeleri açısından türkiye ve gelişmiş ülkelerle kıyaslaması. İsletme ve İktisat Calsmalar Dergisi, 1(1), $12-25$.

KAP (2020). Şirket bildirimleri. İstanbul: KAP. Erişim adresi: thttps://www.kap.org.tr/tr/bildirimsorgu?member $=4028 \mathrm{e} 4 \mathrm{a} 141 \mathrm{da} 49 \mathrm{e} 50141 \mathrm{e} 08580772 \mathrm{~b} 86 \&$ disclosureClass $=\mathrm{FR}$. 


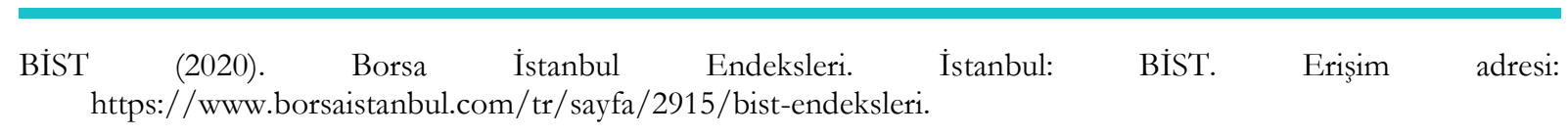

\section{EXTENDED ABSTRACT}

In the globalizing world, companies' ability to compete and survive is closely related to innovation based on scientific and technological advances. The capacity of companies to produce innovation is directly proportional to economic resources and their efficient use. With R\&D investments, it is aimed to improve production processes, to develop new products and thus to achieve profitability by increasing sales. The impact of R\&D expenditures is very important in terms of sustainability and competitive advantage. The creation of new products or services, innovation in existing products or services can be expressed as R\&D. R\&D expenditures create results that will affect the competitiveness of the company. Increasing the sales of the companies and ensuring a sustainable profitability are likely to be among these results. For this reason, R\&D investments make companies more advantageous than their competitors and contribute to the technological progress of companies. Today, this situation also manifests itself with the increasing share of companies' R\&D expenditures. Most of the investment budgets of companies that want to follow innovation technologically and want to develop continuously are allocated to $\mathrm{R} \& \mathrm{D}$. Researching the contribution of $\mathrm{R} \& \mathrm{D}$ expenditures to companies, which have such a high share in the companies' budget, constitutes the basis of the study. What is the effect of $R \& D$ expenses on company profitability? The study sought an answer to this question.

The purpose of this study is to determine the effect of R\&D expenditures on sales, net profit and gross profit. For this purpose, the effect of R\&D expenditures of companies included in the BIST 30 index on net profit, gross profit and sales was analyzed through static panel data analysis. In this study, the effect of R\&D expenditures on net profit, gross profit and sales in the 2009-2019 period is examined for 14 companies in BIST 30. R\&D expenditures are considered as an independent variable. Accordingly, net profit, gross profit and sales were included in the analysis as dependent variables. As an independent variable, the effect of $\mathrm{R} \& \mathrm{D}$ expenditures on net profit, gross profit and sales was tried to be determined. There are many studies in domestic and foreign literature on the impact of $R \& D$ expenditures on profitability and financial performance. Some of these studies show that there is a strong relationship between $R \& D$ expenditures and profitability and sales (Scherer, 1965; Geroski, \& Toker, 1996; Erdoğan, \& Yamaltdinova, 2019; Uzun Kocamış, \& Güngör, 2014). This study was carried out to determine whether this relationship is also valid for companies traded on BIST 30. In this way, the effects of $\mathrm{R} \& \mathrm{D}$ expenditures of companies will be determined and it will be possible to compare them with other study results.

In this study, static panel data analysis was used to analyze the effect of $R \& D$ investments of companies on net profit, gross profit and sales. Before starting the analysis for the coefficient estimates, the cross section dependency was tested in the series and the appropriate panel unit root test was decided. Afterwards, F test, LR test and Hausman tests were used to select the appropriate panel data method. According to the findings obtained on the basis of the models in the previous stage, it was decided that fixed effects and random effects models could be used. For each model, variance, autocorrelation and inter-unit correlation problems were investigated and our analysis was concluded by using appropriate resistive estimators according to the obtained results. It has been determined that these problems exist in all models by performing variance, autocorrelation and inter-unit correlation tests for each model. In order to obtain consistent and effective results, predictions are made for the relevant models using DriscollKraay and Beck-Katz estimators.

We can summarize the results we obtained in the analyzes as follows:

1) R\&D expenditures positively and significantly affect net profit, gross profit and sales. 
2) A $1 \%$ increase in $R \& D$ expenditures increases the net profits of companies by approximately $0.78 \%$, gross profits by $0.70 \%$ and sales by $0.28 \%$.

3) While the $R \& D$ expenditures of the companies increase the net profit the most, it increases the sales least. According to the data obtained within the scope of the study, the positive effect of R\&D expenditures on profits and sales is compatible with the literature (Scherer, 1965; Erdoğan, \& Yamaltdinova, 2019; Uzun Kocamış, \& Güngör, 2014; Hajiheydari, Dastgir, \& Soltani, 2011; Günay, Kaygisiz, \& Setting, 2018; Işık, Engeloğlu, \& Kılınç, 2016; Güzen, \& Başar, 2019; Ayaydın, \& Karaaslan, 2014) and some other studies (Coad, \& Rao, 2008).

As a result, it is very important for companies and policy makers to invest more in R\&D expenditures in developing new products and production methods. This will not only provide companies with competitive advantage but also create added value for the national economies. In future studies, it will be possible to investigate the effect of R\&D expenditures on other indices in BIST and to compare the results of the study. 